\title{
A onipresença da essência dos princípios de processo sob a ótica da metafísica
}

DOI: $10.20396 /$ labore.v13i0.8657767

Submetido 04 nov. 2019.

Aceito 10 dez. 2019.

Publicado 26 dez. 2019.
André Munhoz de Argollo Ferrão <https://orcid.org/0000-0003-0687-3622> Universidade Estadual de Campinas / Campinas [SP] Brasil

José Felicio Ribeiro de Cezare <https://orcid.org/0000-0002-3934-2097>

Universidade Estadual de Campinas / Campinas [SP] Brasil

RESUMO

Por uma abordagem sistêmica, transdisciplinar e orientada a processos, este texto foi desenvolvido para apresentar a presença inerente da essência de princípios de processo nas áreas de conhecimento como Ciências Humanas e Ciências Exatas. Devido as suas diferenças na percepção de como a realidade pode ser, este trabalho apresenta a ligação de um processo físico - exemplificando a produção de um objeto - com um processo metafísico, demonstrado pelos sistemas de crenças e filosofias do budismo tibetano e do budismo zen. Estabelecendo-se a relação entre os processos físicos e metafísicos mediante alguns dos princípios utilizados durante as aulas de Abordagem Sistêmica e Pensamento Orientado a Processos, inspirados nos princípios que orientam os estudos da Sociedade Europeia para o Pensamento do Processo. Agregando o pensamento de Whitehead, Russell, Jung, Sidarta, Morin e Krishnamurti.

PALAVRAS-CHAVE

Ensino de ciências. Abordagem sistêmica. Filosofia do processo. Psicologia do processo. Transdisciplinaridade. Matemática.

\section{The omnipresence of the essence of process principles under the metaphysical perspective}

\section{ABSTRACT}

Through a systemic, transdisciplinary and process-oriented approach, this text was developed to present the inherent presence of the essence of process principles in the areas of knowledge such as the Humanities and Exact Sciences. Due to its differences in the perception of how reality can be, this work presents the connection of a physical process - exemplifying the production of an object — with a metaphysical process, demonstrated by the belief systems and philosophies of Tibetan Buddhism and Zen Buddhism. Establishing the relationship between the physical and metaphysical processes through some of the principles used during the Systemic Approach and Process-oriented Thinking classes, inspired by the principles that guide the studies of the European Society for Process Thinking. Aggregating the thought of Whitehead, Russell, Jung, Siddhartha, Morin and Krishnamurti.

\section{KEYWORDS}

Science teaching. Systems approach. Process philosophy. Process psychology. Transdisciplinarity. Mathematics. 


\section{Introducãa}

Este texto desenvolve-se a partir da análise de princípios e conceitos identificadores e pertencentes aos processos de que, teoricamente, o indivíduo possa considerar-se conhecedor, não necessariamente compreendendo-os devido à infinidade de ocorrências. Porém, caso tenha consciência de alguns, serão apresentados método e exemplo de como descrevê-los.

O filosofar, os questionamentos e as novas proposições resultantes dessas análises têm como objetivos derrubar dogmas e paradigmas. A ciência não sendo inflexível como a religião, deve, como princípio, evoluir, não regredir ou se ater ao que não serve mais; entretanto, os valores éticos estarão preservados, respeitados e defendidos.

A estrutura que pode ser reconhecida como processo é uma percepção e uma criação humanas, sendo o recorte identificado apenas como uma pequena parte de um todo, podendo ocorrer em diversas escalas e dimensões.

A origem da noção de princípios relativos aos processos perpassa áreas filosóficas, matemáticas, físicas e metafísicas. Com foco na essência destes princípios, toda a discussão foi embasada. Assim este trabalho foi delineado.

Os processos são identificados em quaisquer situações como fenômenos ou númenos ${ }^{1}$, causas e condições ou consequências, independem de espaço, tempo ou circunstâncias, áreas do saber, etc.

O processo de pensar é êste: se vos faço uma pergunta com a qual estais bem familiarizado, e também com a resposta, respondeis imediatamente; se a pergunta não vos é familiar, bá um intervalo de tempo, uma demora, entre a pergunta e a resposta; a memória está em função; estais indagando, procurando, esperando. Ésse processo, em seu todo, produz um pensamento, uma resposta. Quando chegais ao ponto em que dizeis que realmente não sabeis como deter o pensar, já não ficais esperando que alguém vos mostre como fazể-lo (Jiddu Krishnamurti, 1966).

\section{Princípios de processo e conceitos sistêmicos}

Considerando as diversas metodologias de reflexão, esta análise segue uma sequência espiralada ascendente (Figura 1) propondo uma abstração, um voo sem limites através das reflexões apresentadas e discutidas durante as aulas da disciplina Abordagem Sistêmica e Pensamento Orientado a Processos, ministradas pelo Professor Doutor André Munhoz de Argollo Ferrão, no Instituto de Geociências da Unicamp.

Sendo um ambiente acadêmico, um espaço destinado às ciências, as reflexões remetem a um material próprio, a partir de fontes primárias e secundárias para comprovação ou refutação da análise, e produção de artigos para consolidação e socialização de conhecimento. Ou seja, em formato tradicional é a representação de um processo. As discussões desenvolvem-se a partir:

- do Pensamento Orientado a Processos;

- da Abordagem Sistêmica;

- da Transdisciplinaridade;

- da Complexidade².

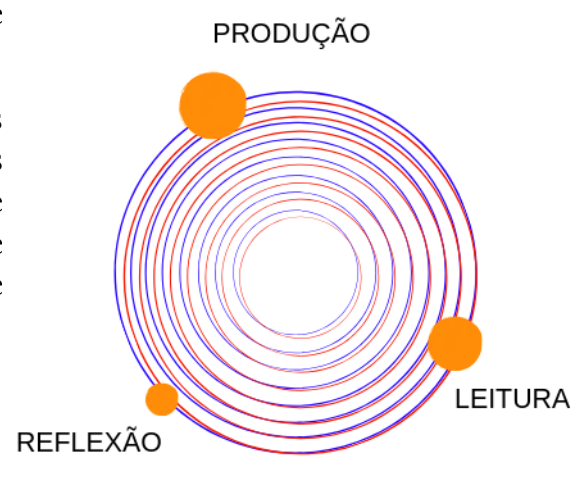

Figura 1. Espiral ascendente de conhecimento. Fonte: Os Autores.

Os princípios de processo nos auxiliam a realizar uma abordagem da realidade, ou seja, tudo aquilo que a mente apreende, seja imaginação, ilusão, pensamento, conhecimento, mitos ou lenda, história, memória, etc. Os princípios estão baseados em quatro conceitos primordiais: $\mathrm{O}$ enfoque de que tudo é processo, pois tudo está em mudança; o pensamento sistêmico, que não nega a racionalidade científica, mas acredita que ela não oferece parâmetros suficientes para o desenvolvimento humano e para descrição do universo

\footnotetext{
${ }^{1}$ De acordo com o "Dicionário de Filosofia", site organizado por Sérgio Biagi Gregório, "Númeno" : "realidade inteligível, objeto da razão (nous) por oposição à realidade sensível. Para Kant, o númeno é o aspecto pelo qual a coisa em si escapa à nossa percepção sensível cujas possibilidades não vão além do fenômeno, que é portanto o único cognoscível” (cf. Durozoi \& Rossel, 1993). “O termo 'númeno' (mais propriamente 'nóumenon') significa 'o que é pensado'. Seu plural 'númenos' (mais propriamente 'noumena'), 'as coisas que são pensadas'. Como 'ser pensado' é entendido aqui como "o que é pensado pela razão" (ou pela intuição intelectual), geralmente se equipara 'númeno' a 'o inteligível'. O mundo dos númenos é, assim, o mundus intelligibilis, contraposto, desde Platão, ao mundus sensibilis, ou mundos dos fenômenos” (cf. Mora, 2004).

${ }^{2}$ De acordo com Edgar Morin (2013), a complexidade é concebida como uma rede não linear na qual os processos ocorrem simultaneamente, interagindo e influenciando a estruturação de um sistema.
} 
material, e por isso deve ser desenvolvida conjuntamente com a subjetividade das artes e das diversas tradições culturais ou mesmo espirituais; a transdiciplinaridade, que é uma abordagem científica que visa a unidade do conhecimento, significando que existe um pensamento organizador que ultrapassa as próprias disciplinas do conhecimento; e por fim, o pensamento complexo, que é um dos pressupostos da transdisciplinaridade e trata de uma nova maneira de perceber e pensar o mundo, saindo de um padrão de pensamento cartesiano-linear, que possui suas raízes em Aristóteles e leva à fragmentação do conhecimento, dividindo-o em partes, negligenciando as relações que existem entre esses conhecimentos e os diferentes contextos, que são essenciais à visão significativa do todo, onde aposta-se a mudança de paradigmas, passando de um paradigma de dominação e poder, de fragmentação, classificação e hierarquização, para um paradigma de cooperação, que valoriza e restabelece as relações, as atitudes significativas.

As reflexões acerca do que poderiam ser Processos caminham no sentido de compreendê-los como princípios variados e não empobrecendo com definições rígidas e absolutas. A descrição de um processo ou processos, ocorre de acordo com a capacidade/habilidade/nível de utilização dos princípios na observação.

O termo processo será aqui identificado por meio de seus princípios — não possibilitando idealizar todos, devido a sua infinidade. São alguns deles:

- Contextualização;

- Mudança;

- Unidade;

- Unicidade;

- Dualidade;

- Exponenciação;

- Inclusão;

- Reconhecimento;

- Fracamente estruturado;

- Tempo zero;

- Integração com energia zero (“insight”);

- Reticência;

- Coevolução;

- Protoiteração;

- Sincronicidade;

- Paralelismo;

- Onipresença.

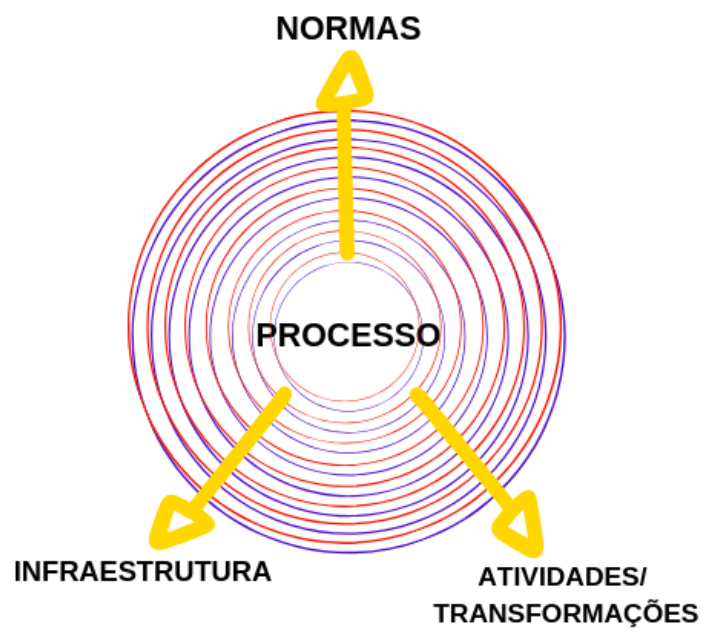

Analisam-se os processos por três eixos (cf. Figura 2):

Figura 2. Processo e seus estruturadores. Fonte: Os Autores.

Em uma percepção mais tradicional, a compreensão dos processos — independente das características, área do saber, circunstâncias, etc., — encontra sua base representada pelo recorte apresentado na Figura 3.

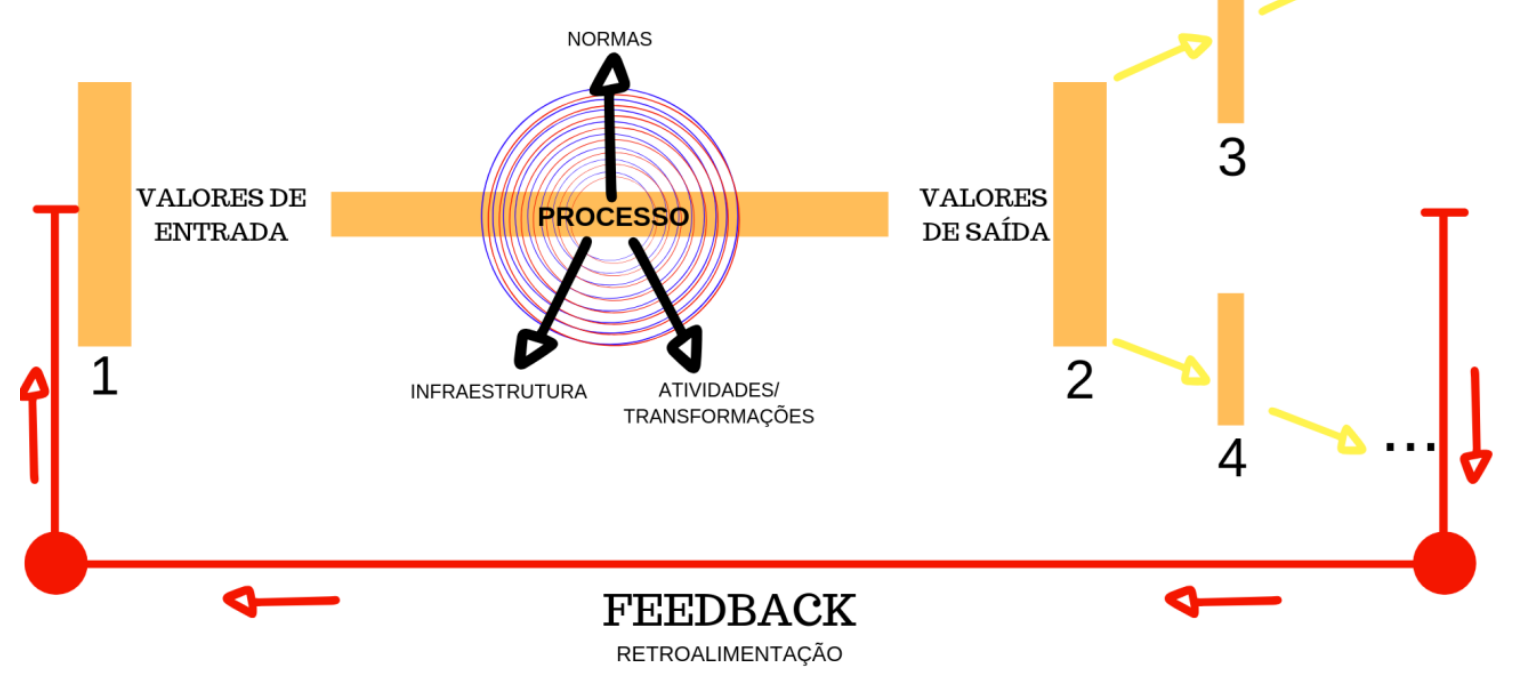

Figura 3. Exemplo de recorte tradicional de um processo. Fonte: Os Autores. 
O modelo representado na Figura 3 procura traduzir o que seria uma noção de processo, onde há:

- Valores de entrada;

- Processo de produção, criação, desenvolvimento;

- Valores de saída (que continuam em processo, no mesmo ou em um novo, como Valores de entrada);

- Feedback, informações, instruções que visam a melhorar o processo em questão.

Para a ocorrência do processo - permanecendo numa análise artificial, sendo a existência de um processo inerente a sua percepção ou não —-, deverão existir infraestrutura ${ }^{3}$, normas ${ }^{4}$ e atividades/transformações ${ }^{5}$.

Em um Sistema ${ }^{6}$ cujos processos ocorrem de forma integrada, há sinergia e emergia. Um sistema não necessariamente existe integrado, mas existe. Se não há sinergia, consequentemente submerge.

Um processo pode ser entendido como uma sucessão de estados de mudança ou transformações, regidas por um conjunto de normas (regras ou leis), e que necessitam de uma infraestrutura para que ocorram. Pode-se dizer que tudo o que se conhece é ou pode ser descrito como um processo. Há que se reconhecer alguns princípios de processo, tais como: mudança, unicidade, dualidade, contextualização, inclusão, reconhecimento, fracamente estruturado, sincronia, tempo zero, integração com energia zero, exponenciação, reticência, dentre outros, todos sob múltiplas dimensões (Argollo Ferrão, 2008).

Tem-se como exemplo o corpo humano, no qual - mesmo sem se ter consciência — os processos inerentes à existência humana ocorrem, sejam os processos físicos (quando possíveis os cinco sentidos, respiração, circulação de fluídos, etc.) ou metafísicos (como pensamentos, processos oníricos, espiritualidade, insights).

Os processos existem concomitantemente, em múltiplas escalas, não havendo necessariamente anulação de um para que outro aconteça; todavia, há a interdependência, ou seja, alguns decorrem de outros e possibilitam a existência de outros ainda, e assim por diante.

Exemplificando o termo sistema com ou sem sinergia, pode-se mais uma vez utilizar o corpo humano, com seu sistema circulatório, sistema digestório, sistema respiratório, sistema nervoso, dentre outros. Todos funcionam simultaneamente quando em plena saúde, corpo e mente se desenvolvem normalmente dentro das diretrizes regulamentadas pelos órgãos de saúde, o que se pode reconhecer como sinergia e emergia.

Quando há falhas em um ou mais processos, alguns deles podem se desintegrar, por estarem desregulados ou apenas ter sua existência não considerada em plena saúde, situação que pode desencadear uma doença ou dela provir uma desregulação. Assim, o sistema pode estar bem estruturado com bom funcionamento, ou com mau funcionamento por estar "fracamente estruturado" (este, um princípio de processo) e, em ambos os casos, deixar de funcionar, sendo ou não possível uma nova regulação, reestruturação e retorno ao funcionamento total, parcial ou tornando-se algo novo.

O nascimento do chamado "pensamento científico" se insere em um contexto no qual imaginação, fé, magia, intuição e emoção encontravam-se indissociavelmente interligadas na prática dos "cientistas" (magos, alquimistas, religiosos, artistas). Em sua origem, no século XVII, quando a ciência ainda era considerada uma atividade periférica, os "cientistas", impulsionados por ideias, mitos e até mesmo sonhos (que alguns reconhecem como "inspiração"), eram simultaneamente filósofos e artistas, conforme destaca Edgar Morin em sua reflexão acerca da emergência das ciências da complexidade (Morin, 2008).

Ao conceber a filosofia como atividade vinculada apenas à subjetividade e a arte como mera forma de entretenimento, o pensamento científico vivenciou uma automutilação que impossibilitou a construção de compreensões multidimensionais acerca dos acontecimentos, fenômenos e processos existentes no cotidiano, ou seja, o mundo e a vida. Desse modo, como ironizou Morin (2008, p. 167), "a poesia, a arte, que podem ser toleradas ou mantidas como divertimento, não poderiam ter valor de conhecimento e de verdade". Essa

\footnotetext{
${ }^{3}$ Capital humano, capital financeiro, energia, suporte emocional, suporte social, suporte intelectual, espaço, tempo... ou seja, qualquer elemento que venha a contribuir para com a consolidação do processo requerido, seja este processo químico, físico e/ou metafísico.

${ }^{4}$ Conjunto de regulamentações, regras, legislação, doutrina e/ou metodologia pertinente que possa regulamentar conduzir, educar, fiscalizar, punir, credenciar, fomentar e avalizar o processo almejado.

${ }^{5}$ Modificações, transmutações, redefinições que possuem o objetivo de transformar determinado material, substância e/ou estado em algo diferente, variando em escalas e dimensões, sem juízo de valor.

${ }^{6}$ Pode ser uma união de elementos, preceitos, princípios e/ou processos, concretos ou não, que podem integrar um todo, caótico ou organizado, físico, químico e/ou metafísico.
} 
arrogância do conhecimento científico, que pretendeu ser a única forma de conhecimento verdadeiro, desdobrou-se na propagação de fragmentadas e redutoras visões incapazes de contribuir com alargadas compreensões acerca das misérias e belezas coexistentes em um mundo vivo.

A partir do momento em que, de um lado, aconteceu a disjunção da subjetividade bumana reservada à filosofia ou à poesia e, do outro, a disjunção da objetividade do saber que é próprio da ciência, o conhecimento científico desenvolveu maneiras mais refinadas para conhecer todos os objetivos possiveis, mas se tornou completamente cego na subjetividade humana (Morin, 2008, p. 128).

Surgem no início do século $\mathrm{XX}$ as primeiras formulações que viriam a ser integradas no chamado pensamento sistêmico, em contraposição ao pensamento linear, manifestando-se em distintos ramos da ciência. $\mathrm{Na}$ área da biologia com Kurt Goldstein $(1878-1965)^{7}$ e a sua perspectiva holística, com a noção do organismo compreendido como um sistema (Goldstein, 1934). Ainda na biologia, Ludwig von Bertalanffy (1901-1972) ${ }^{8}$ publicará mais adiante a Teoria Geral dos Sistemas (TGS), que ao longo do século XX tornouse a base de importantes estudos em diferentes áreas do conhecimento (Bertalanffy, 2013). Muitos cientistas passaram a adotar o pensamento sistêmico, e dentre os expoentes dessa nova forma de enxergar o mundo destaca-se Fritjof Capra $^{9}$, com seus clássicos textos que se tornaram verdadeiros pontos de mutação ao elevarem o significado sistêmico - e consequentemente a sua compreensão — de "redes" para o de "teias" (Capra, 2006, 2012). Tornou-se famoso com O Tao da Física (Capra, 2013) que traça um paralelo entre a física moderna e as filosofias orientais tradicionais (o Taoismo de Lao Tsé, o Budismo e o Hinduísmo).

$\mathrm{Na}$ abordagem sistêmica busca-se analisar as partes separadamente, mas sem perder de vista a sua relação com o todo, além, de conceber que o todo compreende relações que não se manifestam nas partes isoladas, e vice-versa. Em suma: a análise das partes em separado revela um conhecimento; a análise das partes em relação com o todo revela um conhecimento com propriedades distintas - sistêmicas, e por fim, a compreensão do todo também revela um conhecimento com propriedades que caracterizam a identidade e a integridade sistêmica.

O pensamento sistêmico trabalha o ordenamento das relações a partir do pensamento linear consolidado por René Descartes (1596-1650) ${ }^{10}$, filósofo, físico e matemático, preocupado com a ordem, a clareza e a distinção, com a sua filosofia positiva e concreta, uma ciência essencialmente prática e não especulativa, interessado em disciplinar a ciência por meio de um bom método, considerado o pai do racionalismo e um dos inventores do método moderno de investigação, que se tornaria universal, inspirado no rigor matemático e racionalista (Descartes, 1996).

\section{A Filosofia e a Psicologia do Processo}

O pensamento complexo não nega os modelos de pensamentos linear e sistêmico. Ele os reconhece como necessários e muito úteis em determinados contextos, todavia dá um passo além: inclui a aleatoriedade, a incerteza, a imprevisibilidade e impossibilidade de separação entre sujeito e objeto. Considera que "homem, máquina e meio ambiente" estão intrinsecamente interligados num mundo que só pode ser percebido a partir de uma visão holística e integradora.

\footnotetext{
${ }^{7}$ Kurt Goldstein — Katovice [Polônia] 06 nov. 1878 / Nova Iorque [EUA] 19 set. 1965 — neurologista e psiquiatra judeu alemão. Pioneiro em neuropsicologia moderna e coeditor do "Journal of Humanistic Psychology". Criou uma teoria holística do organismo, com base na teoria da Gestalt, que influenciou profundamente o desenvolvimento da Gestalt-terapia. Fonte: Wikipédia.

${ }^{8}$ Karl Ludwig von Bertalanffy — Viena [Austria], 19 set. 1901 / Buffalo [EUA] 12 jun. 1972 — biólogo criador da Teoria Geral dos Sistemas (TGS), desenvolveu a maior parte do seu trabalho científico nos Estados Unidos. Por discordar da visão cartesiana do universo, propôs uma abordagem orgânica da biologia com a ideia de que o organismo é um todo maior que a soma das suas partes. Criticou a visão de um mundo dividido em diferentes áreas, como física, química, biologia, psicologia, etc. Ao contrário, sugeriu que o estudo dos sistemas deveria envolver todas as suas interdependências, pois cada elemento integrado a uma unidade funcional maior desenvolve qualidades que não se encontram em seus componentes isolados. Fonte: Wikipedia.

${ }^{9}$ Fritjof Capra - Viena [Austria] 01 fev.1939 - físico teórico e escritor, vive em Berkeley [California / EUA] onde trabalha e promove a educação ecológica. O Tao da Física o deixa famoso mundialmente ao apresentar pontos comuns entre as abordagens oriental e ocidental da realidade. Em outra referência essencial para o pensamento sistêmico — O Ponto de Mutação, cujo nome foi extraído de um hexagrama do I Ching - Capra compara o pensamento cartesiano, reducionista, modelo para o método científico desenvolvido nos últimos séculos, com o paradigma emergente do século XX, holista ou sistêmico, que vê o todo como indissociável, de modo que o estudo das partes não permite conhecer o funcionamento do organismo em sua plenitude. Fonte: Wikipedia.

${ }^{10}$ René Descartes - La Have en Touraine (atual Descartes) [Franca] 31 mar. 1596 / Estocolmo [Suécia] 11 fev. 1650 - filósofo, físico e matemático francês. Notabilizou-se na filosofia e na ciência, mas também na matemática por sugerir a fusão da álgebra com a geometria (o que gerou a geometria analítica e o sistema cartesiano de coordenadas, que leva o seu nome). Descartes é considerado um dos pensadores mais importantes e influentes da História do Pensamento Ocidental. Fonte: Wikipedia.
} 
Admite-se a importância de diferentes modelos de pensamento que, juntamente com a transdiciplinaridade, se complementam. Assim como a necessidade de reduzir o objeto a variáveis, concebê-las analítica e criticamente, há que se uni-las e entender as relações que possuem entre si num sistema, bem como buscar a compreensão do todo e das suas relações com as partes.

É importante buscar a previsibilidade, a ordenação e uma classificação do mundo. Em alguns casos tratase mesmo de uma questão de sobrevivência. Mas não é somente assim que se avança no conhecimento. Há que se abandonar a ilusão de que se pode ter controle e previsibilidade absolutos sobre o mundo. A razão não é uma "lei divina" capaz de prover todas as soluções para os mais complexos problemas da Humanidade. As Teorias não-lineares podem colaborar para com o avanço do conhecimento e ao mesmo tempo intensificar ainda mais essa busca... num processo sem fim.

Debater a presença, existência e/ou percepção de princípios de processos, até mesmo a essência destes visto que não se define, para evitar um possível engessamento do pensar - é um trabalho filosófico profundo e complexo.

A busca por uma verdade, uma origem e as buscas pelas possibilidades de futuro sempre pautaram o campo filosófico. Desde o pensamento pré-socrático, compreender a realidade tem sido base do pensamento filosófico; entretanto, as modificações no método dessa compreensão acenam para uma aceitação das mudanças, como as referências principais para apreender e explicar a realidade.

É interessante perceber a similaridade entre os estudos da disciplina Abordagem Sistêmica e o Pensamento Orientando a Processos e os princípios de processos analisados por ela, ambos, oriundos de um espaço mais voltado para a objetividade - que transitou durante algum tempo somente entre as áreas da Engenharia — com a Filosofia de Processos ${ }^{11}$. O que não é acaso.

Alfred North Withehead (1861-1947) junto de seu aluno Bertrand Arthur William Russell (1872-1970) escreveram Principia Mathematica12, obra originalmente publicada entre 1910 e 1913, em que filosofia e matemática são trabalhadas concomitantemente e relaciona a matemática com as ciências naturais ${ }^{13}$. Whitehead (1978), quando delineia sua filosofia de processos, passa a analisar o físico pelo metafísico, ou seja, as mudanças psicológicas interferem diretamente no cotidiano, a realidade deixa de ser algo imóvel, tudo é transitório: um lápis, uma cadeira, um universo são processos orgânicos e anacrônicos.

Quando se opõe a Aristóteles (2002)14, Withehead (1978) afirma o papel importantíssimo das ideias na sociedade e sua responsabilidade nas mudanças sociais. Totalmente contrário ao materialismo histórico de Marx (2010 / 1a ed., 1843) ${ }^{15}$, critica ainda em seu trabalho - como Marx o faz quando diz que "a religião é o ópio do povo" - a maneira como as religiões desenvolvem seu papel alienatório ao imobilizar a compreensão da realidade, negando qualquer mudança ou processos existentes.

Sua análise parte da lógica empregada no paradoxo do barbeiro, desenvolvido por Russell: "Quem fará a barba ao barbeiro que tem na janela da loja uma placa a dizer: 'Faço a barba a todos os homens da cidade que não se barbeiam sozinhos, e só a estes"'16. Sendo este paradoxo uma tentativa de explicar o paradoxo dos conjuntos: "O conjunto de todas as coisas que não são maçãs, não pode ser uma maçã". Dessa maneira, tem de ser membro de si próprio. Considere-se então o conjunto de todos os conjuntos que não são membros deles mesmos. Poderá ser membro de si mesmo.

\footnotetext{
11 A instituição atual de referência em produção acadêmica no campo da Filosofia de Processo é a European Society for Process Thought (Sociedade Europeia para o Pensamento do Processo), estabelecida sobre o pensamento do filósofo inglês Alfred North Whitehead.

12 Whitehead \& Russell (2019).

13 Gardner, H. (1995). A Nova Ciência da Mente (trad. Cláudia M. Caon). São Paulo: Edusp.

${ }^{14}$ Ver: Aristóteles (2002). Metafísica (2a ed.). São Paulo: Edições Loyola. Tradução, introdução e comentários de Giovani Reale.

Aristóteles (384 a.C. / 322 a.C.), filósofo grego do período clássico da Grécia antiga, fundador da escola peripatética e do Liceu, foi aluno de Platão e professor de Alexandre, o Grande. Escreveu sobre física e metafísica, legislação, ética e governo, economia, linguística, drama, poesia e música, lógica e retórica, biologia e zoologia. Juntamente com Sócrates e Platão, Aristóteles é visto como um dos fundadores da filosofia ocidental. Fonte: Wikipedia.

${ }^{15}$ Karl Heinrich Marx — Tréveris [Alemanha] 05 mai. 1818 / Londres [Inglaterra] 14 mar. 1883 — filósofo, sociólogo, historiador, economista, jornalista e revolucionário socialista. Nascido na Prússia, mais tarde se tornou apátrida e passou grande parte de sua vida em Londres, no Reino Unido. A obra de Marx em economia estabelece uma base para o entendimento sobre o trabalho e sua relação com o capital. Autor de vários livros, sendo O Manifesto Comunista (1848) e O Capital (1867-1894) os mais proeminentes. Fonte: Wikipedia.

${ }^{16}$ Gardner, M. (1993). Ah, apanhei-te! Lisboa: Gradiva.
} 
Dessa maneira, Whitehead (1978) coloca a metafísica, a filosofia, a matemática, as ciências naturais e a lógica na sua percepção de mudanças e as essências nelas presentes ao analisar a ideia de deus no mundo ocidental e a ideia de mundo:

Enquanto o mundo temporal é concebido como uma autossuficiência completa do ato criador, explicável por sua derivação de um princípio último que é, por sua vez, eminentemente real e motor imóvel, não podemos escapar desta conclusão: o melhor que nós poderíamos dizer desta tormenta é: "ele dá aos seus bem-amados — o sol." Essa é a mensagem das religiões de tipo budista e, num certo sentido, ela é verdadeira. Nessa discussão final, é-nos necessário perguntar se os princípios metafísicos levam a crer que ele exprime a verdade. A complexidade do mundo deve se refletir na resposta. É infantil entrar no domínio do pensamento com a questão simplista: "de que o mundo é feito?" A tarefa da razão é sondar a fundo as profundezas da multilateralidade das coisas. Para questões de vastos alcances, nós não esperamos senão respostas simples. Quanto mais profundo penetrarmos em nossa consideração, há sempre, além dela, distâncias que bloqueiam nossa visão (Whitehead, 1978, p. 84).

Para uma compreensão mais abrangente do mundo, da realidade e da sociedade, é necessário entender através de princípios, os processos que são perceptíveis. De acordo com o exemplo citado, o aprofundamento, a abordagem sistêmica para a tentativa de compreensão de um ou mais processos, dependem da variedade de maneiras como estes princípios ou essências de princípios de processos podem ser reunidos e estudados.

Corroborando as ideias apresentadas, há outro campo de estudos que se debruça sobre tais aspectos: a psicologia de processos, ou psicologia orientada a processos. Dialogando com a filosofia de processos, sua contemporânea, a psicologia de processos denominada assim por Arnold Mindell (1982), integra aspectos físicos e metafísicos relacionando o mundo onírico e o mundo sinestésico ${ }^{17}$ aos seus processos, e apresenta o seu humano como um sistema no modelo citado por Bertalanffy (2013), que abarca esses dois mundos.

A proposição de Mindell (1982) surge a partir da obra de Carl Gustav Jung (1875-1961)18, considerado fundador dessa psicologia, que introduz o conceito de individuação como base do processo de desenvolvimento humano: "A individuação é o processo transformacional de integração do consciente com o inconsciente pessoal e coletivo" (Jung, 1962, p. 301). Agregando em seu trabalho os princípios de processos (precisamente a essência dos princípios) norteados por Whitehead e conectando com sua análise conceitual psicológica erigida nos conceitos de arquétipo, personalidade introvertida/extrovertida, inconsciente coletivo, consciência onírica ${ }^{19}$ e utilizando como base a filosofia oriental, mas precisamente o budismo tibetano ${ }^{20}$, Jung traz na psicologia orientada a processos o ser humano como um ser holístico. Na tentativa de apresentar alguns recortes artificiais dos processos contidos na abordagem sistêmica do ser humano, que, em sua maioria não são perceptíveis como númenos, mas são em alguns casos entendidos apenas como fenômenos, Jung (2017) avalia dentro de sua psicologia os inúmeros processos físicos e metafísicos existentes, conscientes ou não e como compreendê-los:

Quando alguma coisa escapa da nossa consciência, essa coisa não deixou de existir, do mesmo modo que um automóvel que desaparece na esquina não se desfez no ar. Apenas o perdemos de vista. Assim como podemos, mais tarde, ver novamente o carro, também reencontramos pensamentos temporariamente perdidos.

Parte do inconsciente consiste, portanto, de uma profusão de pensamentos, imagens e impressões provisoriamente ocultos e que, apesar de terem sido perdidos, continuam a influenciar nossas mentes conscientes. Um homem desatento on "distraído" pode atravessar uma sala para buscar alguma coisa. Ele para, parecendo perplexo; esquecen o que buscava. Suas mãos tateiam pelos objetos de uma mesa como se fosse um sonâmbulo; não se lembra do seu objetivo inicial mas ainda se deixa, inconscientemente, guiar por ele. Percebe então o que queria. Foi o seu inconsciente que o ajudou a se lembrar.

Se observarmos o comportamento de uma pessoa neurótica podemos vê-la fazendo muitas coisas de modo aparentemente intencional e consciente. No entanto, se a questionarmos, descobriremos que ou não tem consciência alguma das ações praticadas ou então que pensa em coisas bem diferentes. Ouve mas está surda, vể mas está cega, sabe e parece ignorante (Jung, 2017, p. 35).

\footnotetext{
${ }^{17}$ Mindell, A. (1982). O corpo onírico: O Papel do corpo no revelar do si-mesmo (Maria Silvia Mourão Netto, Trad.). São Paulo: Summus.

${ }^{18}$ Carl Gustav Jung - Kesswil [Suíça] 26 jul. 1875 / Küsnacht [Suíça] 06 jun. 1961 — psiquiatra e psicoterapeuta, fundou a psicologia analítica, propôs e desenvolveu os conceitos de personalidade extrovertida e introvertida, arquétipo e inconsciente coletivo. Seu trabalho tem sido influente na psiquiatria, psicologia, ciência da religião, literatura e áreas afins. Fonte: Wikipedia.

${ }^{19}$ Jung, C. G. (1986). Memórias, sonhos, reflexões (Aniela Jaffé, Org.) (Dora Ferreira da Silva, Trad.). Rio de Janeiro: Nova Fronteira.

${ }^{20}$ Jung, C. G. (2017). O Homem e seus Símbolos (3a ed. esp. brasileira) (Maria Lúcia Pinho, Trad.). Rio de Janeiro: Harper Collins.
} 
A compreensão apenas do fenômeno em si, sem uma abordagem sistêmica, profunda torna apenas o superficial como o real absoluto:

\begin{abstract}
A ciência só se ocupa com a ideia média de um carvalho, de um cavalo, ou de uma pessoa, mas não com sua singularidade. Além disso, é quase impossivel descrever um ser humano individualizado, uma vez que não temos pontos de referência fora da esfera humana. Por isso, não sabemos o que é o ser humano. Do ponto de vista da ciência, o indivíduo é desprezível ou mera curiosidade. Mas do ponto de vista subjetivo, isto é, do ponto de vista do próprio indivíduo, ele é o mais importante, pois é o portador da vida, e seu desenvolvimento e aperfeiçoamento são de suprema importância. [...] Todos os critérios da individuação são necessariamente subjetivos e estão fora dos propósitos da ciência (Jung, 2003, pp. 43-44).
\end{abstract}

Faz-se necessário a compreensão dos processos através dos princípios que facilitam sua percepção, estruturando-os na maneira de organizar o pensamento mantendo-o coerente no entendimento de um processo específico. Assim, apreendendo cada etapa ou cada processo será possível entender - não ainda em sua totalidade - o sistema. Um exemplo oferecido por Jung (2017), através dos princípios de sua psicologia, propõe conhecer um processo que estava obscuro num momento inconsciente de um indivíduo:

\begin{abstract}
Lembro-me de uma mulber que chegou à clínica em estado de letargia. Quando, no dia seguinte, recobrou a consciência, sabia quem era mas não sabia onde estava, nem como e por que ali se encontrava; não se lembrava sequer da data. No entanto, depois que eu a hipnotizei, disse-me por que ficara doente, como chegara à clinica e quem a recebera. Todos esses detalbes puderam ser comprovados. Ela foi capaz inclusive de dizer a hora em que chegara à clínica, porque havia um relógio no hall de entrada. Hipnotizada, sua memória mostrava-se tão clara como se tivesse estado totalmente consciente o tempo inteiro (Jung, 2017, p. 36).
\end{abstract}

Os princípios utilizados na abordagem utilizada por Jung (2017) aumentaram a compreensão de outros pequenos processos (recortes tradicionais), para compreender um processo maior: a chegada da paciente letárgica à clínica. Esses princípios ou sua essência tiverem como base a diminuição na profusão de pensamentos e a atenção plena ao momento presente.

Como apresentado, a inflexibilidade, o engessamento do processo observado, seja o mundo, a realidade, um lápis, uma cadeira, um universo, impedem um entendimento mais amplo, mais rico. Tudo pode ser visto como processo e, para facilitar essa percepção, será dado exemplo de como processos e seus princípios ou essências de princípios de processos perpassam qualquer estudo ou teoria.

\title{
4. 0 Nirvana e as essências de princípios observados nos processos
}

Talvez o princípio que melhor se adequa ao termo processo seja a impermanência, princípio que representa uma constante sucessão de estados de mudança. A impermanência também se apresenta como um ponto principal na compreensão de si mesmo nos métodos de elevação de consciência presentes nos ensinamentos budistas. Nos últimos anos, uma estratégia de monetização destes métodos recebeu o nome de Mindfulness21.

No século VI a.C. surge, no que hoje se conhece como Nepal, Sidarta Gautama, um jovem nobre, um príncipe que abdica de sua vida cheia de riquezas para buscar o que chamou de iluminação ou Nirvana ${ }^{22}$.

Sua história começa com a sua mãe recebendo a anunciação por um elefante branco de que ela dará a luz a um ser divino, um ser iluminado que estará livre do samsara, o ciclo de mortes e renascimentos causado pelo apego àquilo que não "existe realmente". Sidarta cresceu em um castelo e sob a proteção do pai, sem conhecer a velhice e a morte, assim como qualquer tipo de sofrimento. Mas, num insight, resolve sair pelo mundo, conhece a velhice, a fome, a pobreza e a morte. Torna-se um eremita e busca, através de métodos e princípios de processo (meditação/Mindfulness), compreender qual a razão do sofrimento. Quando consegue, desperta como o Buda ${ }^{23}$, um ser divino que transcende barreiras, um ser perfeito, capaz de realizar o que quiser.

\footnotetext{
${ }^{21}$ Mindfulness (Atenção plena), segundo Michael Chaskalson, é “a qualidade da conscientização que ocorre quando prestamos atenção a nós mesmos, aos outros e ao mundo que nos cerca de uma certa maneira” (Chaskalson, 2014, p.14).

${ }^{22}$ De acordo com Monja Coen, o Nirvana é aquietar a mente, encontrar a verdade, reconhecer que somos a Verdade. Se você viver no caminho da harmonia, tudo ficará bem.

${ }^{23}$ O nome Buda deriva da palavra sânscrita Bodhi, nome de um tipo de árvore sob a qual Sidarta Gautama, também conhecido como Tathagata, tornou-se um ser iluminado.
} 
A iluminação, ou Nirvana, será alcançada através de um recorte de um processo apresentado por Buda como Caminho Óctuplo24, onde a compreensão e aplicação da impermanência é essencial.

Outra prática que se relaciona aos princípios citados são as Seis Paramitas ou Seis Perfeições25. Este processo em etapas tem como objetivo "alcançar o outro lado" (na tradução do sânscrito para o português), ou seja, a cada parte do processo, os valores de entrada e saída se modificam numa espiral ascendente para aqueles que já alcançaram um nível avançado de compreensão dos processos vivenciados, diferindo um pouco do Caminho Óctuplo, que é totalmente entendido como um só processo em execução, com um único valor de saída, liberto de qualquer "defeito". Ambos oferecem princípios, normas, atividades e possibilidades de infraestrutura.

$\mathrm{Na}$ Figura 4 e na Tabela 1, os princípios de processos já mencionados estão relacionados aos presentes no Caminho Óctuplo e aos que se encontram nas Seis Paramitas, exemplificando quais seriam os Valores de entrada $\times$ Processo (Infraestrutura, Normas, Atividades/Transformações) $\times$ Valores de saída.

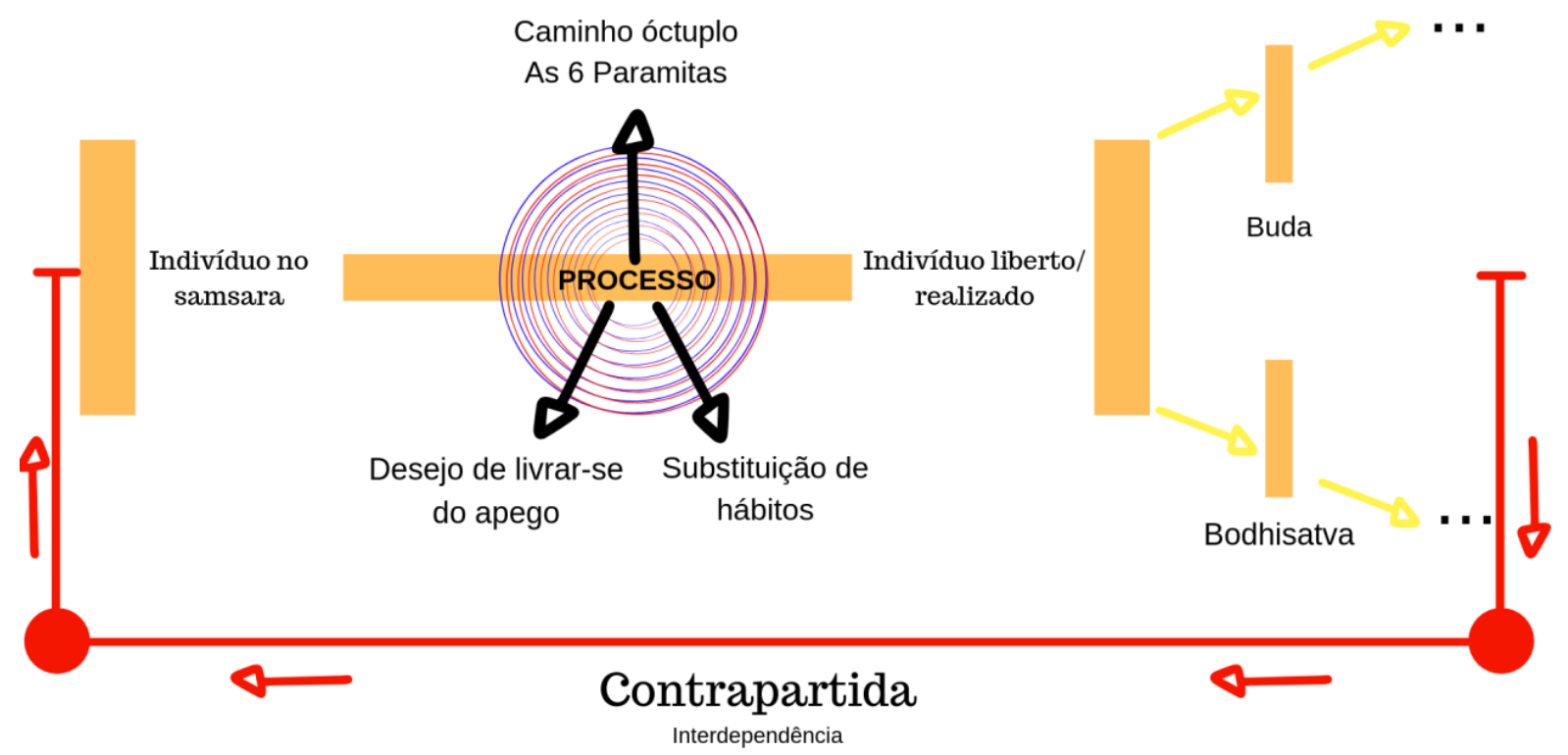

Figura 4. Exemplo de recorte tradicional de um processo metafísico, neste caso, a eliminação do apego ao sofrimento, escapando ao ciclo do samsara e alcançando a iluminação ou dissolução na vacuidade. Fonte: Os Autores.

Tabela 1. Relação de alguns princípios de processo com o Caminho Óctuplo e com as Seis Perfeições (Paramitas). Fonte: Os Autores.

\begin{tabular}{|c|c|c|c|c|c|}
\hline \multicolumn{6}{|c|}{ Relação Princípios x Caminho Óctuplo x Seis Paramitas } \\
\hline \multicolumn{2}{|r|}{ Valores de entrada } & \multicolumn{3}{|c|}{ Processo } & \multirow{2}{*}{$\begin{array}{c}\text { Valores } \\
\text { de saída }\end{array}$} \\
\hline & Indivíduo no samsara & Infraestrutura & Normas & Atividades & \\
\hline \multicolumn{2}{|r|}{ Princípios } & \multicolumn{2}{|c|}{ Caminho óctuplo } & \multirow{2}{*}{\multicolumn{2}{|c|}{ Seis Paramitas }} \\
\hline 1 & Contextualização & \multicolumn{2}{|c|}{ Compreensão Correta (Samyag-drsti) } & & \\
\hline 2 & Mudança & \multicolumn{2}{|c|}{$1 ; 2 ; 5 ; 7 ; 9 ; 13 ; 15 ; 17$} & \multicolumn{2}{|c|}{ Generosidade } \\
\hline 3 & Unidade & \multicolumn{2}{|c|}{ Pensamento Correto (Samyak-samkalpa) } & \multicolumn{2}{|c|}{$1 ; 2 ; 3 ; 4 ; 5 ; 7$} \\
\hline
\end{tabular}

${ }^{24}$ Mizuno, K. (2003). Essentials of Buddhism - Basic Terminology and Concepts of Buddhist Philosophy and Practice [Tradução e revisão de Monja Coen]. São Paulo: s./n.

25 Rinchen, G. S. (2009). As seis perfeições: como atingir o bem-estar supremo [Comentários de Geshe Sonam Rinchen. Organização Ruth Sonam. Tradução de Christina Wangmo Carvalho]. São Paulo: WMF Martins Fontes. 


\begin{tabular}{|c|c|c|c|c|}
\hline 4 & Unicidade & & $2 ; 3 ; 4 ; 5 ; 6 ; 7 ; 8 ; 9 ; 11 ; 12 ; 15 ; 17$ & Disciplina ética \\
\hline 5 & Dualidade & 3 & Fala Correta (Samyag-vac) & todos \\
\hline 6 & Exponenciação & & $1 ; 2 ; 6 ; 7 ; 8 ; 9 ; 11 ; 12 ; 13 ; 14 ; 15 ; 16 ; 17$ & Paciência \\
\hline 7 & Inclusão & 4 & Ação Correta (Samyak-karmanta) & $1 ; 2 ; 3 ; 7 ; 8$ \\
\hline 8 & Reconhecimento & & $2 ; 6 ; 7 ; 8 ; 9 ; 10 ; 11 ; 15 ; 17$ & Esforço entusiástico \\
\hline 9 & Fracamente estruturado & 5 & Meio de Vida Correto (Samyag-ajiva) & $4 ; 6$ \\
\hline 10 & Tempo “0” & & todos & Concentração \\
\hline 11 & Integração com energia " 0 " & 6 & Esforço Correto (Samyak-vyayama) & $1 ; 2 ; 7 ; 8$ \\
\hline 12 & Reticência & & $2 ; 3 ; 9 ; 10 ; 11 ; 13 ; 14 ; 15 ; 17$ & Sabedoria \\
\hline 13 & Coevolução & 7 & Atenção Correta (Samyak-smrti) & $1 ; 2 ; 7 ; 8$ \\
\hline 14 & Protointeração & & $1 ; 2 ; 3 ; 10 ; 11 ; 17$ & \\
\hline 15 & Sincronicidade & 8 & Concentração Correta (Samyak-samadhi) & \\
\hline 16 & Paralelismo & & $1 ; 2 ; 3 ; 7 ; 8 ; 9 ; 10 ; 11 ; 15 ; 17$ & \\
\hline 17 & Presença constante & & & \\
\hline
\end{tabular}

\section{Conclusão}

A compreensão do que pode vir a ser um processo transita e encontra estruturação nos mais diversos ambientes. Termos que, notadamente, pertencem às esferas empresariais, tecnológicas e administrativas encontram seus semelhantes em áreas que, por negligência, intencional ou ingênua, não foram analisadas.

Seja um sistema integrado ou não, como uma empresa com seu sistema administrativo e seu sistema financeiro, ou uma doutrina filosófica com seu sistema hierárquico e sistema de crenças, em ambas — apesar das discrepâncias inerentes e explícitas — os princípios de processo e a concepção de sistema estão presentes.

Definições criadas para atender à necessidade de formular e estruturar conceitos acabam por empobrecer e limitar o quão ampla e abrangente é a ocorrência de processos, percebidos apenas no nível de atenção que a mente humana consegue captar.

Os bilhões de trilhões de processos físicos, químicos e metafísicos, dos quais não temos consciência, acabam por influenciar direta e indiretamente nossos pensamentos e ações coletivas e individuais, cujos resultados podem desencadear outros milhares de milhões de novos processos, e as consequências, assim como os processos, podem ser infinitas. Quanto maior for o número de pequenos processos (recorte tradicional) compreendidos, maior será a capacidade de elucidação de problemas existentes e a criação de novos caminhos de soluções.

\section{Referências}

Argollo Ferrão, A. M. de (2008). El pensamiento orientado a procesos valorizando los paisajes culturales en las distintas agroindustrias. I Seminário de Património Agroindustrial Paisajes Culturales (Anales, pp. 1-13), 2008, Mendoza, Argentina.

Aristóteles (2002). Metafísica (2a ed., Giovani Reale Trad., introd., e comentários). São Paulo: Edições Loyola.

Aristóteles. Disponível em https://pt.wikipedia.org/wiki/Aristóteles . Acesso 26 out. 2019.

Bertalanffy, K. L. von (2013). Teoria Geral dos Sistemas : fundamentos, desenvolvimento e aplicações (7a ed., F. M. Guimarães, Trad.). Petrópolis [RJ]: Vozes. (Obra original publicada em1968).

Bohm, D., \& Krishnamurti, J. (1984). A Eliminação do Tempo Psicológico: Diálogos entre J. Krishnamurti e David Bohm. São Paulo: Cultrix. 
Capra, F. (2013). O Tao da Física : uma análise dos paralelos entre física moderna e o misticismo oriental (1a reimpr. da 2a ed., de 2011, J. F. Dias, Trad.). São Paulo: Cultrix. (Obra original publicada em 1975).

Capra, F. (2012). O Ponto de Mutação (30a ed., A. Cabral, Trad.). São Paulo: Cultrix. (Obra original publicada em 1982).

Capra, F. (2006). A Teia da Vida : uma nova compreensão científica dos seres vivos (10a reimpr. da 1a ed., de 1997, N. R. Eichemberg, Trad.). São Paulo: Cultrix. (Obra original publicada em 1996).

Carl Gustav Jung. Disponível em https://pt.wikipedia.org/wiki/Carl_Gustav_Jung . Acesso 26 out. 2019.

Chaskalson, M. (2017). Mindfulness em oito semanas: Um plano simples e revolucionário para iluminar sua mente e trazer serenidade para a sua vida ( C. G. Duarte \& E. G. Duarte, Trad.). São Paulo: Pensamento.

Descartes, R. (1996). Discurso do Método (M. E. G. G. Pereira, Trad.). São Paulo: Martins Fontes. (Obra original publicada em 1637).

Durozoi, G. \& Roussel, A. (1993). Dicionário de Filosofia (M. Appenzeller, Trad.). Campinas : Papirus.

Fritjof Capra. Disponível em https://pt.wikipedia.org/wiki/Fritjof_Capra . Acesso 21 out. 2019.

Gardner, H. (1995). A Nova Ciência da Mente (C. M. Caon, Trad.). São Paulo: Edusp.

Gardner, M. (1993). Ah, apanhei-te! Lisboa: Gradiva.

Goldstein, K. (1934). The Organism: A Holistic Approach to Biology Derived from Pathological Data in Man. New York: Zone Books.

Gregório, S. B. (s./d.). Dicionário de Filosofia. Disponível em https://sites.google.com/view/sbgdicionariodefilosofia/ página-inicial?authuser=0 . Acesso 20 out. 2019.

Jung, C. G. (2017). O Homem e seus Símbolos (3a ed. esp. brasileira) (M. L. Pinho, Trad.). Rio de Janeiro: Harper Collins.

Jung, C. G. (2003). Cartas III (1956-1961)(W. Mcguirre, Org.) (E. Orth, Trad.). Petrópolis [RJ]: Vozes.

Jung, C. G. (1986). Memórias, sonhos, reflexões (A. Jaffé, Org.) (D. F. da Silva, Trad.). Rio de Janeiro: Nova Fronteira.

Jung, C. G. (1962). Symbols of Transformation: An analysis of the prelude to a case of schirophrenia (Vol. 2, R. F. C. Hull, Trans.). New York: Harper \& Brothers.

Karl Heinrich Marx. Disponível em https://pt.wikipedia.org/wiki/Karl_Marx . Acesso 26 out. 2019.

Karl Ludwig von Bertalanffy. Disponível em https://pt.wikipedia.org/wiki/Ludwig_von_Bertalanffy . Acesso 21 out. 2019.

Krishnamurti, J. (2016). O findar do tempo (H. Veloso, Trad.). São Paulo: Instituição Cultural Krishnamurti.

Krishnamurti, J. (1984). O mistério da compreensão (H. Veloso, Trad.). São Paulo: Cultrix.

Kurt Goldstein. Disponível em https://pt.wikipedia.org/wiki/Kurt_Goldstein . Acesso 21 out. 2019.

Marx, K. (2010). Crítica da filosofia do direito de Hegel (3a. ed.) (R. Enderle \& L. de Deus, Trad.). São Paulo: Boitempo. (Obra original publicada em 1843).

Mindell, A. (1982). O corpo onírico: O Papel do corpo no revelar do si-mesmo (Maria Silvia Mourão Netto, Trad.). São Paulo: Summus.

Mizuno, K. (2003). Essentials of Buddhism: Basic Terminology and Concepts of Buddhist Philosophy and Practice. (Monja Coen, Trad. e revis.). São Paulo: Kosei Publishing.

Mora, J. F. (2004). Dicionário de Filosofia. São Paulo : Loyola.

Morin, E. (2013). Educação e Complexidade: os Sete Saberes e outros ensaios (6a. ed.) (M. C. Almeida \& E. A. Carvalho, Orgs.) (E. A. Carvalho, Trad.). São Paulo: Cortez.

Morin, E. (2008). Introdução ao pensamento complexo. Porto Alegre: Instituto Piaget.

René Descartes. Disponível em https://pt.wikipedia.org/wiki/René_Descartes . Acesso 21 out. 2019.

Rinchen, G. S. (2009). As seis perfeições: como atingir o bem-estar supremo. Comentários de Geshe Sonam Rinchem (R. Sonam, Org.) (C. W. Carvalho, Trad.). São Paulo: WMF Martins Fontes.

Trungpa, C. (2015). Louca sabedoria (E. Pinheiro, Trad.). Teresópolis [RJ]: Lúcida Letra.

Whitehead, A. N. (1978). Process and reality. New York: Free Press.

Whitehead, A. N., \& Russell, B. A. W. (2019). Principia Mathematica (Vol. I.). Eastford [EUA]: Martino Fine.

Yün, H. (2011). Budismo: Significados Profundos (2a. ed., revis. e ampl.). São Paulo: Escrituras. 